\title{
Hyperglycaemia is associated with all-cause and cardiovascular mortality in the Hoorn population: the Hoorn Study
}

\author{
F. de Vegt, J. M. Dekker, H. G. Ruhé, C. D. A. Stehouwer, G. Nijpels, L. M. Bouter, R.J. Heine \\ Institute for Research in Extramural Medicine, Vrije Universiteit, Amsterdam, The Netherlands
}

\section{Abstract}

Aims/hypothesis. The degree of glycaemia has been shown to be associated with all-cause and cardiovascular mortality in diabetic subjects. Whether this association also exists in the general population is still controversial. We studied the predictive value of fasting plasma glucose, 2-hour post-load glucose and $\mathrm{HbA}_{1 \mathrm{c}}$ in a population-based cohort of 2363 older (50-75 years) subjects, without known diabetes.

Methods. Relative risks (RR) of all-cause and cardiovascular mortality were estimated by Cox proportional hazards model, adjusting for age and sex, and additionally for known cardiovascular risk factors.

Results. During 8 years of follow-up, 185 subjects died; 98 of cardiovascular causes. Fasting plasma glucose was only predictive in the diabetic range, although the risks started to increase at about $6.1 \mathrm{mmol} / \mathrm{l}$. Postload glucose and $\mathrm{HbA}_{1 \mathrm{c}}$ values were, even within the non-diabetic range, associated with an increased risk ( $p$ for linear trend $<0.05$ ). These increased risks were mostly, but not completely, attributable to known cardiovascular risk factors. After exclusion of subjects with newly diagnosed diabetes or with pre-existent cardiovascular disease $(n=551)$, a $5.8 \mathrm{mmol} / \mathrm{l}$ increase of post-load glucose (corresponding to two standard deviations of the population distribution) was associated with a higher age-adjusted and sex-adjusted risk of all-cause (RR 2.24) and cardiovascular mortality (RR 3.40) $(p<0.05)$. After additional adjustment for known cardiovascular risk factors, these relative risks were still statistically significant, with values of 2.20 and 3.00 respectively $(p<0.05)$.

Conclusion/interpretation. High glycaemic variables, especially 2 -h post-load glucose concentrations and to a lesser extent $\mathrm{HbA}_{1 \mathrm{c}}$ values, indicate a risk of allcause and cardiovascular mortality in a general population without known diabetes. [Diabetologia (1999) 42: 926-931]

Keywords Glucose, $\mathrm{HbA}_{1 \mathrm{c}}$, hyperglycaemia, cardiovascular mortality, Hoorn population.
Longitudinal epidemiological studies have shown that the risk of cardiovascular disease (CVD) mortality in diabetic subjects is more than double that of subjects without diabetes $[1,2]$. In diabetic patients, the risk of CVD mortality increases with increasing

Received: 18 January 1999 and in revised form: 22 April 1999

Corresponding author: F. de Vegt MSc, Institute for Research in Extramural Medicine, Vrije Universiteit, Van der Boechorststraat 7, 1081 BT Amsterdam, The Netherlands Abbreviations: FPG, Fasting plasma glucose; $2 \mathrm{~h}-\mathrm{PG}, 2$-h postload glucose; CVD, cardiovascular disease; RR, relative risk. plasma glucose concentrations and $\mathrm{HbA}_{1 \mathrm{c}}$ values $[3,4]$.

Whether the associations between glycaemic variables and CVD mortality are also present in non-diabetic subjects is still controversial; the results of prospective studies on hyperglycaemia and CVD mortality are inconsistent. Some observed no effect $[5,6]$, some observed linear associations $[7,8]$ and some a threshold effect $[5,7,9,10]$. Comparison between the different studies is very difficult because different indicators of glycaemia are presented and because of the differences in follow-up time and sex and age of the subjects. For a good comparison, the relation of glycaemic variables with all-cause and CVD mortali- 
ty should be investigated and compared in the same study group. Therefore, we compared the associations between fasting plasma glucose (FPG), 2-h post-load glucose (2h-PG) and $\mathrm{HbA}_{1 \mathrm{c}}$ with all-cause and CVD mortality in a population-based study of 2363 men and women, aged 50-75 years, without known diabetes. Furthermore, we investigated whether the associations observed were independent of known cardiovascular risk factors.

\section{Subjects and methods}

Subjects. The Hoorn Study is a cohort study on glucose intolerance in a Dutch population of older subjects, which started in 1989. The study cohort and baseline measurements have been described in detail previously [11]. Briefly, 3553 men and women aged 50-75 years were randomly selected from the population register of the middle-sized Dutch town of Hoorn. Of the 2540 subjects $(71.5 \%)$ who agreed to participate, 56 non-Caucasians were excluded. Thus, the study cohort of the Hoorn Study consisted of 2484 men and women. Subjects who were already using insulin, blood glucose lowering agents or a diet for diabetes were classified as 'known diabetic patients' $(n=90)$. This group was excluded from the present analyses. We also excluded 17 subjects with missing information on $\mathrm{HbA}_{1 \mathrm{c}}$ or plasma glucose values. The subjects for whom the causes of death could not be retrieved $(n=14)$ were excluded in all analyses so that the study cohort was the same in all analyses. Consequently, the analyses were done in the remaining 2363 subjects. All subjects had given their written informed consent. The study was approved by the ethics committee of the Vrije Universiteit Hospital.

Follow-up. In 1995, the follow-up of the Hoorn Study cohort was started in cooperation with the population register of the city of Hoorn, the local hospital and general practitioners. Vital status was obtained from the register for the time since the start of the Hoorn Study. Since 1995, a prospective registration of vital status has been implemented. Causes of death were extracted from the medical records of the general practitioners and the local hospital and were coded according to the International Classification of Diseases, Injuries, and Causes of Death, ninth revision (ICD-9) [12] by two of the authors. Cardiovascular mortality was defined as ICD-9 codes 390-459 ('Diseases of the circulatory system') or 798 ('Sudden death, cause unknown'), because sudden death in general is of CVD origin [13]. Coding was checked in a sample $(n=23)$ by a certified nosologist from the local hospital; agreement within selected categories was nearly perfect. Of those who had moved out of Hoorn $(n=160 ; 6.8 \%)$, only the vital status was checked in the population registers of the cities to which the subjects had moved. Eight subjects $(0.3 \%$ of the study cohort) were lost to follow-up.

Glycaemic variables and examinations. A fasting blood sample was taken from all subjects and subsequently, an oral 75-g glucose load was given. Fasting (FPG) and 2-h post-load plasma glucose concentrations (2h-PG) were determined with a glucose dehydrogenase method (Merck, Darmstadt, Germany). Glycated haemoglobin $\left(\mathrm{HbA}_{1 \mathrm{c}}\right)$ was determined by ion-exchange high performance liquid chromatography, using a Modular Diabetes Monitoring System (Bio-Rad, Veenendaal, the Netherlands). Fasting specific insulin concentration was quantified with an insulin-specific double-anti- body radioimmunoassay (antibody SP21; Linco, St. Louis, Mo., USA).

Blood pressure (BP) was measured twice on the right arm with subjects sitting in a chair, using a random-zero sphygmomanometer (Hawksley-Gelman Ltd, Lancing, UK). The average of two measurements was used for analyses. Subjects were considered hypertensive when systolic BP was $160 \mathrm{mmHg}$ or more, diastolic BP $95 \mathrm{mmHG}$ or more and/or when using anti-hypertensive medication [14]. Weight and height were measured with subjects wearing underwear only and body mass index (BMI) was calculated as body weight divided by height $\left(\mathrm{m}^{2}\right)$. Waist and hip circumferences were measured according to a standardised procedure [15]. Waist-hip ratio (WH ratio) was defined as waist circumference divided by hip circumference. Total and HDL-cholesterol were determined from fasting blood samples by enzymatic techniques (Boehringer-Mannheim, Mannheim, Germany). The Friedewald formula was used to calculate the concentration of LDLcholesterol [16]. This formula was not applied in subjects with serum triglyceride concentrations more than $8.0 \mathrm{mmol} / \mathrm{l}$ $(n=6)$.

Information on current cigarette smoking habits (yes/no) was obtained by questionnaire. Information on pre-existent cardiovascular diseases (myocardial infarction, angina pectoris, stroke and peripheral atherosclerotic disease) was obtained from the subjects using a translated version of the Rose questionnaire from the London School of Hygiene [17].

Statistical methods. Subjects were categorised according to approximate tertiles of $\mathrm{HbA}_{1 \mathrm{c}}, \mathrm{FPG}$ and $2 \mathrm{~h}-\mathrm{PG}$. Subsequently, the highest tertiles of FPG and $2 \mathrm{~h}-\mathrm{PG}$ were divided into subgroups with cut-off points used for the clinical diagnosis of impaired fasting glucose (IFG), impaired glucose tolerance (IGT) and diabetes: for FPG $6.1-7.0 \mathrm{mmol} / \mathrm{l}$ (IFG) and $7.0 \mathrm{mmol} / \mathrm{l}$ or more diabetes, and for $2 \mathrm{~h}-\mathrm{PG} 7.8-11.1 \mathrm{mmol} / \mathrm{l}$ (IGT) and $11.1 \mathrm{mmol} / \mathrm{l}$ or more diabetes $[18,19]$. The highest tertile of $\mathrm{HbA}_{1 \mathrm{c}}$ was divided into two subgroups by the cut-off of $6.5 \%$, corresponding to the optimal target for the treatment of diabetes [20]. Baseline characteristics were calculated for categories of $\mathrm{HbA}_{1 \mathrm{c}}$, FPG and 2h-PG. Age-adjusted and sexadjusted differences relative to the lowest categories of $\mathrm{HbA}_{1 \mathrm{c}}$, FPG and 2h-PG were tested with analysis of covariance (ANCOVA). Regression analysis with ordered categories was used to test linear trends in baseline characteristics over the categories of $\mathrm{HbA}_{1 \mathrm{c}}$, FPG and $2 \mathrm{~h}-\mathrm{PG}$, adjusting for age and sex. Hazard ratios for all-cause and cardiovascular mortality, which can be interpreted as relative risks (RRs), and $95 \%$ confidence intervals (CI) were estimated by Cox proportional hazards model, adjusting for age and sex. Linear trends were tested using ordered categories in the Cox regression models. The known CVD risk factors hypertension, WH ratio, triglycerides, LDL-cholesterol and cigarette smoking were, in addition, considered as confounders because these variables had the strongest influences on the estimated RRs in bivariate analyses. Because of differences in the units of the glycaemic variables, we also compared RRs expressed per two standard deviations (SD) of the population distribution. Pearson's correlation coefficients were calculated for the correlations between FPG, 2 h-PG and $\mathrm{HbA}_{1 \mathrm{c}}$. To assess whether effect modification was present, we included product terms between sex and glycaemic variables. Analyses were done using the Statistical Package for the Social Sciences (SPSS for Windows 6.1) [21]. $P$-values were based on two-sided tests and the cut-off point for statistical significance was 0.05 . 
Table 1. Baseline characteristics in categories of $\mathrm{HbA}_{1 \mathrm{c}}$

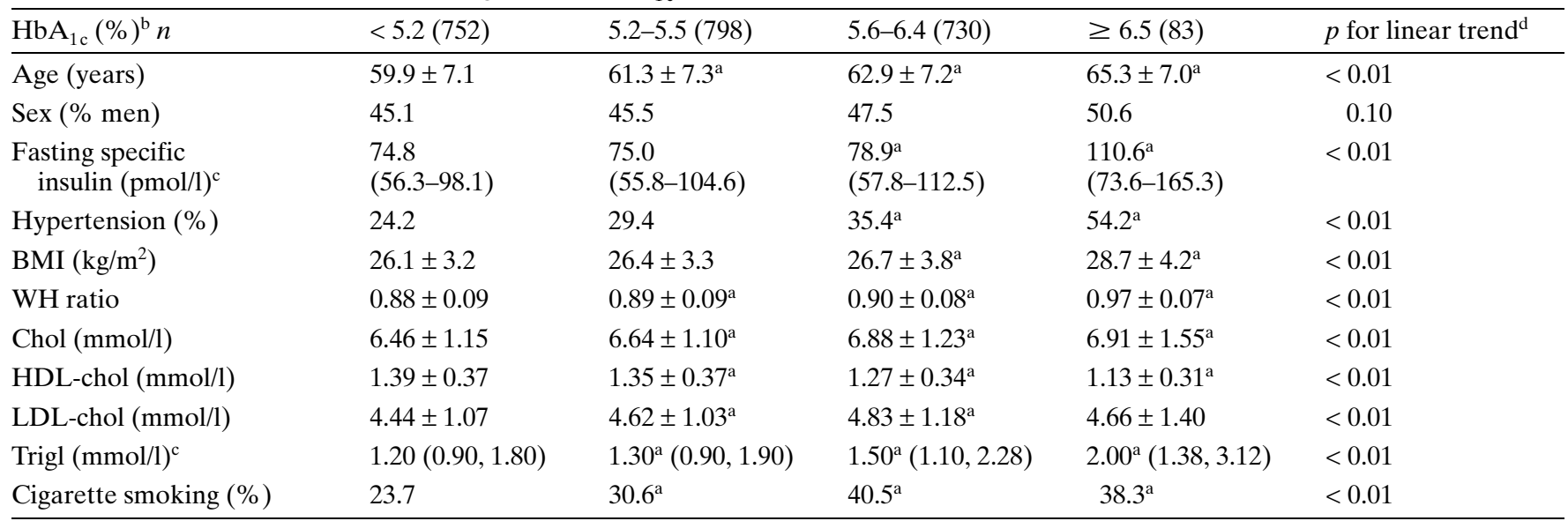

chol: cholesterol, HDL-chol: high density lipoprotein cholesterol, LDL-chol: low density lipoprotein cholesterol, trigl.: triglycerides

Results are means \pm SD, percentage or median (20,80 percentile)

${ }^{\text {a }}$ Significantly different from $\mathrm{HbA}_{1 \mathrm{c}}<5.2$, adjusted for age and sex

$\mathrm{b}$ Tertiles of $\mathrm{HbA}_{1 \mathrm{c}}$ were made and the highest tertile was divided into 2 subgroups by the cut-off point $6.5 \%$

c Tested after log-transformation

d Adjusted for age and sex

Table 2. Relative risk ( $95 \% \mathrm{CI}$ ) of all-cause and cardiovascular mortality by categories of $\mathrm{HbA}_{1 \mathrm{c}}$

\begin{tabular}{|c|c|c|c|c|c|}
\hline $\mathrm{HbA}_{1 \mathrm{c}}(\%)^{\mathrm{a}} n$ & $<5.2(752)$ & $5.2-5.5(798)$ & $5.6-6.4(730)$ & $\geq 6.5(83)$ & $p$ for linear trend \\
\hline all-cause mortality $(n)$ & 41 & 55 & 72 & 17 & \\
\hline model 1 & 1 & $1.03(0.68-1.55)$ & $1.24(0.84-1.84)$ & $2.23(1.24-4.01)$ & 0.03 \\
\hline model 2 & 1 & $0.94(0.62-1.40)$ & $0.97(0.65-1.45)$ & $1.38(0.74-2.55)$ & 0.59 \\
\hline model 1 & 1 & $1.56(0.85-2.84)$ & $1.69(0.93-3.06)$ & $3.58(1.60-8.00)$ & $<0.01$ \\
\hline model 2 & 1 & $1.30(0.71-2.38)$ & $1.09(0.59-2.00)$ & $1.79(0.77-4.16)$ & 0.49 \\
\hline
\end{tabular}

model 1: adjusted for age and sex

model 2: additionally adjusted for hypertension, waist : hip ra-

tio, triglycerides, LDL-cholesterol and cigarette smoking

\section{Results}

Follow-up was complete by October 1997. During this follow-up period of 8 years, 185 subjects died. For 98 subjects (53\%), the cause of death was cardiovascular. Mean $\mathrm{HbA}_{1 \mathrm{c}}$ in the study cohort of 2363 subjects was $5.4 \pm 0.7 \%$, mean FPG $5.6 \pm 1.1 \mathrm{mmol} / \mathrm{l}$ and mean $2 \mathrm{~h}-\mathrm{PG} 6.1 \pm 2.9 \mathrm{mmol} / \mathrm{l}$. The Pearson's correlation coefficient was 0.66 between $\mathrm{HbA}_{1 \mathrm{c}}$ and FPG, 0.57 between $\mathrm{HbA}_{1 \mathrm{c}}$ and $2 \mathrm{~h}-\mathrm{PG}$ and 0.75 between FPG and 2h-PG (all $p<0.01$ ).

Table 1 shows baseline characteristics in categories of $\mathrm{HbA}_{1 \mathrm{c}}$. Compared with subjects with $\mathrm{HbA}_{1 \mathrm{c}}$ values less than 5.2 , subjects with $\mathrm{HbA}_{1 \mathrm{c}} 6.5 \%$ or more were statistically significantly older, had a higher BMI, and were more often hypertensive and cigarette smokers. They also had a higher fasting specific insulin concentration, a higher $\mathrm{WH}$ ratio and a more unfavourable lipid profile $(p<0.05)$. For all these variables a linear trend was observed with increasing $\mathrm{HbA}_{1 \mathrm{c}}(p<0.01)$. For the categories of FPG and $2 \mathrm{~h}-\mathrm{PG}$ the same linear patterns were seen, although
${ }^{\mathrm{a}}$ Tertiles of $\mathrm{HbA}_{1 \mathrm{c}}$ were made and the highest tertile was divided into 2 subgroups by the cut-off point $6.5 \%$

no statistically significant linear trends were observed for LDL-cholesterol and cigarette smoking (data not shown).

Table 2 shows RRs for all-cause and cardiovascular mortality in categories of $\mathrm{HbA}_{1 \mathrm{c}}$.

As expected, the highest age-adjusted and sexadjusted RRs were found for subjects with $\mathrm{HbA}_{1 \mathrm{c}}$ $6.5 \%$ or more: 2.23 (95\% CI 1.24-4.01) for allcause mortality and 3.58 (95\% CI 1.60-8.00) for CVD mortality. The risks of all-cause and CVD mortality started to increase in the lower range of $\mathrm{HbA}_{1 \mathrm{c}}$ ( $p$ for linear trend $\left.<0.05\right)$. After additional adjustment for known CVD risk factors, the RRs were, however, smaller and no longer statistically significant.

The RRs for categories of FPG are presented in Table 3. Age and sex-adjusted RRs start to increase, although not statisitically significantly, at FPG $6.1 \mathrm{mmol} / \mathrm{l}$ or more. After additional adjustment for known cardiovascular risk factors, the associations between FPG and all-cause and CVD mortality disappeared. Subjects with FPG 5.2-6.0 mmol/1 had 
Table 3. Relative risk ( $95 \% \mathrm{CI}$ ) of all-cause and cardiovascular mortality by categories of fasting plasma glucose

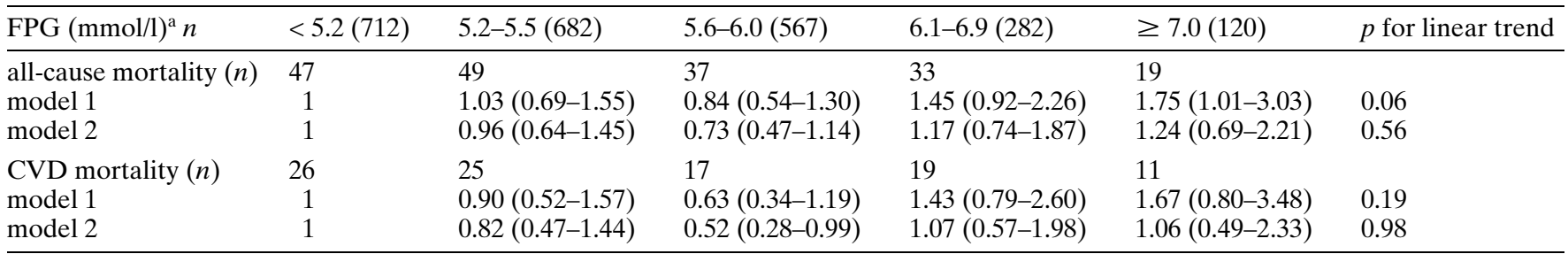

model 1: adjusted for age and sex

model 2: additionally adjusted for hypertension, waist : hip ra-

tio, triglycerides, LDL-cholesterol and cigarette smoking a Tertiles of FPG were made and the highest tertile was divided into subgroups by the cut-off points 6.1 and $7.0 \mathrm{mmol} / \mathrm{l}$

Table 4. Relative risk (95\% CI) of all-cause and cardiovascular mortality by categories of 2-h plasma glucose

\begin{tabular}{|c|c|c|c|c|c|c|}
\hline $2 \mathrm{~h}-\mathrm{PG}(\mathrm{mmol} / \mathrm{l})^{\mathrm{a}} n$ & $<4.9(811)$ & $4.9-6.2(749)$ & $6.3-7.7(438)$ & $7.8-11.0(255)$ & $\geq 11.1(110)$ & $p$ or linear trend \\
\hline all-cause mortality $(n)$ & 39 & 62 & 34 & 30 & 20 & \\
\hline model 1 & 1 & $1.57(1.04-2.35)$ & $1.30(0.82-2.08)$ & $1.73(1.06-2.84)$ & $2.74(1.57-4.79)$ & $<0.01$ \\
\hline model 2 & 1 & $1.45(0.96-2.19)$ & $1.15(0.71-1.86)$ & $1.48(0.88-2.49)$ & $2.03(1.10-3.75)$ & 0.07 \\
\hline model 1 & 1 & $2.11(1.18-3.77)$ & $1.58(0.81-3.09)$ & $1.92(0.93-3.94)$ & $3.31(1.50-7.31)$ & 0.02 \\
\hline model 2 & 1 & $1.77(0.99-3.19)$ & $1.25(0.63-2.48)$ & $1.48(0.70-3.16)$ & $2.22(0.94-5.23)$ & 0.24 \\
\hline
\end{tabular}

model 1: adjusted for age and sex

model 2: additionally adjusted for hypertension, waist : hip ratio, triglycerides, LDL-cholesterol and cigarette smoking a Tertiles of $2 \mathrm{~h}-\mathrm{PG}$ were made and the highest tertile was divided into subgroups by the cut-off points of 7.8 and $11.1 \mathrm{mmol} / \mathrm{l}$ lower RRs than those with FPG less than $5.2 \mathrm{mmol} / \mathrm{l}$, although these RRs were not statistically significant.

Table 4 shows RRs for categories of $2 \mathrm{~h}-\mathrm{PG}$. Statistically significant age-adjusted and sex-adjusted associations for all-cause and CVD mortality were found for subjects with $2 \mathrm{~h}-\mathrm{PG} 11.1 \mathrm{mmol} / \mathrm{l}$ or more (RR 2.74; 95\% CI $1.57-4.79$ and 3.31 ; $95 \%$ CI $1.50-7.31)$. These associations were still (borderline) significant after additional adjustment for known CVD risk factors. The risks were increased for $2 \mathrm{~h}-\mathrm{PG} 4.9 \mathrm{mmol} / \mathrm{l}$ or more ( $p$ for linear trend $<0.03$; age-adjusted and sex-adjusted).

Because of the linear trends observed for $\mathrm{HbA}_{1 \mathrm{c}}$ and $2 \mathrm{~h}-\mathrm{PG}$, we used continuous glycaemic variables in subsequent analyses. Table 5 shows the results of these analyses, with RRs expressed per two standard deviations (SD) of the population distribution. The strongest age-adjusted and sex-adjusted RRs were found for 2h-PG: 1.54 for all-cause mortality and 1.64 for CVD mortality $(p<0.05)$ per $5.8 \mathrm{mmol} / \mathrm{l}$ increase, corresponding to two SD of the population distribution. After additional adjustment for hypertension, WH ratio, triglycerides, LDL-cholesterol and cigarette smoking, the RRs remained statistically significant $(p<0.05)$. After exclusion of newly diagnosed diabetic subjects, with FPG or $2 \mathrm{~h}-\mathrm{PG}$ values in the diabetic range $(n=164)[18,19]$, the age-adjusted and sex-adjusted RRs were even higher for $2 \mathrm{~h}-\mathrm{PG}$ as well as for $\mathrm{HbA}_{1 \mathrm{c}}$, but only statistically significant for $2 \mathrm{~h}-\mathrm{PG}$ (all-cause mortality RR $1.78 ; 95 \% \mathrm{CI}$ 1.06-2.98). When subjects with pre-existent cardiovascular diseases $(n=433)$ were excluded [17], the
RRs for $\mathrm{HbA}_{1 \mathrm{c}}$ and for $2 \mathrm{~h}-\mathrm{PG}$ were also higher than the RRs of the total study cohort and were all statistically significant $(p<0.05)$. When both groups (subjects with glucose values in the diabetic range $[18,19]$ and subjects with pre-existent CVD) [17] were excluded, the RRs were higher than the RRs of the total study cohort, and statistically significant for $2 \mathrm{~h}-\mathrm{PG}$ $(p<0.05)$.

\section{Discussion}

In this follow-up study of 2363 older men and women, $2 \mathrm{~h}-\mathrm{PG}$ and $\mathrm{HbA}_{1 \mathrm{c}}$ were, even in the non-diabetic range, associated with increased risk of all-cause and CVD mortality. This increased risk was mostly, but not completely, attributable to known CVD risk factors.

The Hoorn Study is a prospective study of subjects who were randomly selected from the population register of Hoorn; thus selection bias can be excluded. Glucose concentrations and $\mathrm{HbA}_{1 \mathrm{c}}$ values were assessed only once. In a sub-group of 1109 subjects, in whom a second OGTT was done after 2 to 6 weeks, the intra-individual coefficient of variation was $6.5 \%$ for FPG and $16.7 \%$ for $2 \mathrm{~h}-\mathrm{PG}$, indicating larger variability for $2 \mathrm{~h}-\mathrm{PG}$ than for FPG [22]. This is in line with observations in other studies [23,24]. This variability may have caused some random misclassification in the categories of $2 \mathrm{~h}-\mathrm{PG}$ and to a lesser extent in the categories of FPG. Unfortunately, no duplicate measurements of $\mathrm{HbA}_{1 \mathrm{c}}$ were done. In the Is- 
Table 5. Relative risk for all-cause and cardiovascular mortality $(95 \% \mathrm{CI})$ for $\mathrm{HbA}_{1 \mathrm{c}}$ and $2 \mathrm{~h}-\mathrm{PG}$ as continuous variables expressed per 2 standard deviations ${ }^{\mathrm{a}}$

\begin{tabular}{|c|c|c|}
\hline & $\mathrm{HbA}_{1 \mathrm{c}}$ & $2 \mathrm{~h}-\mathrm{PG}$ \\
\hline $\begin{array}{l}\text { Total cohort }(n=23 \\
\text { all-cause mortality } \\
\text { model } 1 \\
\text { model } 2\end{array}$ & $\begin{array}{l}1.39(1.15-1.67) \\
1.22(0.97-1.53)\end{array}$ & $\begin{array}{l}1.54(1.28-1.85) \\
1.43(1.15-1.79)\end{array}$ \\
\hline $\begin{array}{l}\text { CVD mortality } \\
\text { model } 1 \\
\text { model } 2\end{array}$ & $\begin{array}{l}1.51(1.20-1.88) \\
1.34(0.99-1.82)\end{array}$ & $\begin{array}{l}1.64(1.29-2.08) \\
1.56(1.16-2.11)\end{array}$ \\
\hline $\begin{array}{l}\text { Subjects with newly } \\
\text { all-cause mortality } \\
\text { model } 1 \\
\text { model } 2\end{array}$ & $\begin{array}{l}\text { gnosed diabetes } \\
1.46(0.93-2.29) \\
1.06(0.66-1.68)\end{array}$ & $\begin{array}{l}\mathrm{d}(n=2199)^{\mathrm{b}} \\
1.78(1.06-2.98) \\
1.54(0.89-2.68)\end{array}$ \\
\hline $\begin{array}{l}\text { CVD mortality } \\
\text { model } 1 \\
\text { model } 2\end{array}$ & $\begin{array}{l}1.71(0.91-3.20) \\
0.96(0.50-1.83)\end{array}$ & $\begin{array}{l}1.76(0.86-3.60) \\
1.32(0.61-2.87)\end{array}$ \\
\hline $\begin{array}{l}\text { pre-existent CVD e } \\
\text { all-cause mortality } \\
\text { model } 1 \\
\text { model } 2\end{array}$ & $\begin{array}{l}\operatorname{ded}(n=1930)^{c} \\
1.49(1.16-1.91) \\
1.32(1.00-1.75)\end{array}$ & $\begin{array}{l}1.75(1.40-2.19) \\
1.71(1.32-2.20)\end{array}$ \\
\hline $\begin{array}{l}\text { CVD mortality } \\
\text { model } 1 \\
\text { model } 2\end{array}$ & $\begin{array}{l}1.92(1.47-2.51) \\
1.62(1.18-2.23)\end{array}$ & $\begin{array}{l}2.24(1.70-2.94) \\
2.12(1.54-2.91)\end{array}$ \\
\hline $\begin{array}{l}\text { Subjects with newly } \\
\text { CVD excluded }{ }^{\mathrm{b}, \mathrm{c}}( \\
\text { all-cause mortality } \\
\text { model } 1 \\
\text { model } 2\end{array}$ & $\begin{array}{l}\text { gnosed diabetes } \\
1812) \\
1.61(0.93-2.79) \\
1.25(0.71-2.20)\end{array}$ & $\begin{array}{l}\text { with pre-existent } \\
2.24(1.20-4.18) \\
2.20(1.11-4.33)\end{array}$ \\
\hline $\begin{array}{l}\text { CVD mortality } \\
\text { model } 1 \\
\text { model } 2\end{array}$ & $\begin{array}{l}2.12(0.94-4.77) \\
1.16(0.51-2.63)\end{array}$ & $\begin{array}{l}3.40(1.35-8.53) \\
3.00(1.08-8.30)\end{array}$ \\
\hline
\end{tabular}

model 1: adjusted for age and sex

model 2: additionally adjusted for hypertension, waist : hip ratio, triglycerides, LDL-cholesterol and cigarette smoking

a $2 \mathrm{SD}$ : for $\mathrm{HbA}_{1 \mathrm{c}} 1.4 \%$ and for $2 \mathrm{~h}-\mathrm{PG} 5.8 \mathrm{mmol} / \mathrm{l}$

${ }^{\mathrm{b}} \mathrm{FPG} \geq 7.0 \mathrm{mmol} / \mathrm{l}$ and $/$ or $2 \mathrm{~h}-\mathrm{PG} \geq 11.1 \mathrm{mmol} / 1$

${ }^{\mathrm{c}}$ Obtained from the subjects using a translated version of the Rose questionnaire from the London School of Hygiene

lington Diabetes Survey, however, the coefficient of variation for $\mathrm{HbA}_{1 \mathrm{c}}$ among subjects without known diabetes was $13.7 \%$ [25].

In our study, the predictive values of FPG, $2 \mathrm{~h}-\mathrm{PG}$ and $\mathrm{HbA}_{1 \mathrm{c}}$ were compared in the same general population without known diabetes. Results of previous studies on the associations of glycaemic variables with (cardiovascular) mortality have been inconclusive. In a cross-sectional study, the association between three glycaemic variables and prevalent coronary heart disease (CHD) were compared. A linear increase of CHD over quartiles of both $2 \mathrm{~h}-\mathrm{PG}$ and $\mathrm{HbA}_{1}$, with $2 \mathrm{~h}-\mathrm{PG}$ being the best predictor, was observed [26]. The results of a combined analysis of the Whitehall study, Paris Prospective study and Helsinki Policemen study have recently been reported. It was found that men in the upper $2.5 \%$ of the FPG and $2 \mathrm{~h}-\mathrm{PG}$ distribution were at higher risk of CVD mortality during 20 years of follow-up than men in the lower $80 \%$ of these distributions [9]. The RRs for subjects in these lower categories were, however, not presented and because of differences in the OGTTs in the three studies mentioned, the distributions of the $2 \mathrm{~h}-\mathrm{PG}$ concentrations were not fully comparable. In the Rancho Bernardo Study, a linear relation was found between FPG and ischaemic heart disease mortality for men but a threshold effect was observed for women [7]. In a Finnish study of 3267 men there was no clear association between post-load glucose concentration and CVD mortality [5] whereas the Honolulu Heart Program showed a linear increase [8]. Less is known about the predictive value of $\mathrm{HbA}_{1 \mathrm{c}}$ in a general population. In one prospective study, $\mathrm{HbA}_{1 \mathrm{c}}$ but not FPG or $2 \mathrm{~h}-\mathrm{PG}$, was related to CVD mortality in women but not in men [10].

In a few studies, which studied the associations of glycaemic variables with CVD mortality separately for men and women, the associations were stronger in women than in men $[2,7,10,27]$. In our study, no clear consistent differences between men and women were observed (all $p$-values for product terms were 0.20 or more; data not shown).

Our study shows no clear independent association between FPG and mortality, although the risk started to increase, though not statistically significantly, at $6.1 \mathrm{mmol} / 1$ or more. In contrast, $2 \mathrm{~h}-\mathrm{PG}$ and $\mathrm{HbA}_{1 \mathrm{c}}$ were associated with mortality even within the nondiabetic range. Significant linear trends were seen for both variables $(p<0.05)$. The increased risk was to a considerable extent attributable to known CVD risk factors, such as WH ratio, hypertension, LDLcholesterol, triglycerides and cigarette smoking, as in other studies [5, 8, 9]. After exclusion of subjects with newly diagnosed diabetes or with pre-existent CVD, a $5.8 \mathrm{mmol} / \mathrm{l}$ increase of $2 \mathrm{~h}-\mathrm{PG}$ (corresponding to $2 \mathrm{SD}$ of the population distribution) was, however, associated with a higher risk of all-cause (RR 2.24) and CVD mortality (RR 3.40) $(p<0.05)$. So it appears that $2 \mathrm{~h}-\mathrm{PG}$, especially, is a good predictor of mortality in subjects without diabetes or CVD. It can be speculated that the lower mortality risk of previously undiagnosed subjects, who were diagnosed with diabetes by the Hoorn Study, was due to the subsequent treatment of CVD risk factors by their general practitioners, who were informed about their diabetic status. After adjustment for known CVD risk factors, the RRs for $2 \mathrm{~h}-\mathrm{PG}$ were still statistically significant, with RRs of 2.20 and 3.00 for all-cause and CVD mortality, respectively $(p<0.05)$.

A possible explanation for these findings could be insulin resistance and the insulin resistance syndrome, a clustering of metabolic disorders, including glucose intolerance, obesity, hypertension and lipid abnormalities [28-30]. Because insulin sensitiviy declines slowly and monotonically with increasing 
2h-PG concentrations, the increased risk associated with $2 \mathrm{~h}-\mathrm{PG}$ could partly be due to this multifaceted syndrome [31]. Additional adjustment of fasting specific insulin did not, however, change the results (data not shown). In addition, the impact of postprandial, or post-load, glucose spikes could also explain our results. A short-term increase in blood glucose concentrations may induce oxidative stress, which might be an important factor in the aetiology of vascular complications in diabetic subjects $[32,33]$.

The increased risk associated with a fasting plasma glucose concentration higher than $6.1 \mathrm{mmol} / \mathrm{l}$, supports the cut-off point which is used for the category 'impaired fasting glucose' in the new ADA-criteria [18]. In addition, the results of this study suggest that an OGTT is also warranted to distinguish subjects with a higher risk for mortality.

In conclusion, high glycaemic variables, especially $2 \mathrm{~h}-\mathrm{PG}$ concentrations and to a lesser extent $\mathrm{HbA}_{1 \mathrm{c}}$ values, may be indicators of increased risk of CVD mortality in a general older population without known diabetes. This may be of value for risk stratification in clinical practice.

Acknowledgements. We would like to thank K. de Molennaar for her assistance in the extraction of medical information in the local hospital of Hoorn. We are also grateful for the help of I. van Dijk for validating the ICD-9 codes and for the cooperation of T. Schoenmaker of the Population Register in Hoorn. C.D. A. Stehouwer was supported by a clinical research fellowship from the Netherlands Organisation for Scientific Research (NWO).

\section{References}

1. Kannel WB, McGee DL (1979) Diabetes and cardiovascular Disease. The Framingham Study. JAMA 241: 2035-2038

2. Pan WH, Cedres LB, Liu K et al. (1986) Relationship of clinical diabetes and asymptomatic hyperglycemia to risk of coronary heart disease mortality in men and women. Am J Epidemiol 123: 504-516

3. Laakso M (1996) Glycemic control and the risk for coronary heart disease in patients with non-insulin-dependent diabetes mellitus. The Finnish Studies. Ann Intern Med 124: 127-130

4. Wei M, Gaskill SP, Haffner SM, Stern MP (1998) Effects of diabetes and level of glycemia on all-cause and cardiovascular mortality. Diabetes Care 21: 1167-1173

5. Pyörälä K (1979) Relationship of glucose tolerance and plasma insulin to the incidence of coronary heart disease; results from two population studies in Finland. Diabetes Care 2: 131-141

6. Ohlson LO, Svärdsudd K, Welin Let al. (1986) Fasting blood glucose and risk of coronary heart disease, stroke and all-casue mortality: a 17-year follow-up study of men born in 1913. Diabet Med 3: 33-37

7. Scheidt-Nave C, Barrett-Connor E, Wingard DL, Cohn BA, Edelstein SL (1991) Sex differences in fasting glycemia as a risk factor for ischemic heart disease death. Am J Epidemiol 133: 565-576

8. Donahue RP, Abbott RD, Reed DM, Yano K (1987) Postchallenge glucose concentration and coronary heart disease in men of Japanese ancestry. Honolulu Heart Program. Diabetes 36: 689-692

9. Balkau B, Shipley M, Jarrett RJ et al. (1998) High blood glucose concentration is a risk factor for mortality in middle-aged nondiabetic men. 20-Year follow-up in the Whitehall Study, the Paris Prospective Study, and the Helsinki Policemen Study. Diabetes Care 21: $360-367$

10. Park S, Barrett-Connor E, Wingard DL, Shan J, Edelstein S (1996) $\mathrm{GHb}$ is a better predictor of cardiovascular disease than fasting or postchallenge plasma glucose in women without diabetes. The Rancho Bernardo Study. Diabetes Care 19: 450-455

11. Mooy JM, Grootenhuis PA, de Vries H et al. (1995) Prevalence and determinants of glucose intolerance in a Dutch Caucasian population. The Hoorn Study. Diabetes Care 18: 1270-1273

12. World Health Organization (1977) International Classification of diseases. 9th edn, vols 1, 2. WHO, Geneva

13. Kannel WB, Plehn JF, Cupples LA (1988) Cardiac failure and sudden death in the Framingham Study. Am Heart J 115: 869-875

14. Working Group on Risk and High Blood Pressure (1985) An epidemiological approach to describing risk associated with blood pressure levels. Final report of the Working Group on Risk and High Blood Pressure. Hypertension 7: 641-651

15. Seidell JC, Cigolini M, Charzewska J, Contaldo F, Ellsinger B, Björntorp P (1988) Measurement of regional distribution of adipose tissue. In: Björntorp P, Rossner S (eds) Obesity in Europe 1. Libbey, London, pp 351-359

16. Friedewald WT, Levy RI, Fredrickson DS (1972) Estimation of the concentration of low-density lipoprotein cholesterol in plasma, without use of the preparative ultracentrifuge. Clin Chem 18: 499-502

17. Rose GA, Blackburn H (1982) Cardiovascular survey methods. Monograph Series No 56, World Health Organization. WHO, Geneva

18. American Diabetes Association (1997) Report of the expert committee on the diagnosis and classification of diabetes mellitus. Diabetes Care 20: 1183-1197

19. World Health Organization (1985) Diabetes Mellitus: Report of a WHO Study Group. Technical Report Series No 127, World Health Organization. WHO, Geneva

20. Alberti KG, Gries FA, Jervell J, Krans HM for the European NIDDM Policy Group (1994) A desktop guide for the management of non-insulin-dependent diabetes mellitus (NIDDM). An update. Diabet Med 11: 899-909

21. Norusis MJ (1990) SPSS for Windows 6.1. SPSS Inc., Chicago

22. Mooy JM, Grootenhuis PA, de Vries $\mathrm{H}$ et al. (1996) Intra-individual variation of glucose, specific insulin and proinsulin concentration measured by two oral glucose tolerance test in a general Caucasian population:the Hoorn Study. Diabetologia 39: 298-305

23. Olefsky JM, Reaven GM (1974) Insulin and glucose responses to identical and oral glucose tolerance tests performed forty-eight hours apart. Diabetes 23: 449-453

24. Feskens EJ, Bowles CH, Kromhout D (1991) Intra- and interindividual variablility of glucose tolerance in an elderly population. J. Clin. Epidemiol. 44: 947-953

25. Forrest RD, Jackson CA, Yudkin JS (1988) The abbreviated glucose tolerance test in screening for diabetes: the Islington Diabetes Survey. Diabet Med 5: 557-561

26. Jackson CA, Yudkin JS, Forrest RD (1992) A comparison of the relationships of the glucose tolerance test and the glycated haemoglobin assay with diabetic vascular disease in the community. The Islington Diabetes Survey. Diabetes Res Clin Pract 17: 111-123

27. Janghorbani M, Jones RB, Gilmour WH, Hedley AJ, Zhianpour M (1994) A prospective population based study of gender differential in mortality from cardiovascular disease and 'all causes' in asymptomatic hyperglycaemics. J Clin Epidemiol. 47: 397-405

28. DeFronzo RA, Ferrannini E (1991) Insulin Resistance: a multifaceted syndrome responsible for NIDDM, obesity, hypertension, dyslipidemia, and atherosclerotic cardiovascular disease. Diabetes Care 14: 173-194

29. Haffner SM (1996) The Insulin Resistance Syndrome revisited. Diabetes Care 19: 275-277

30. Meigs JB, d'Agostino RB Sr, Wilson PW, Cupples LA, Nathan DM, Singer DE (1997) Risk variable clustering in the Insulin Resistance Syndrome. The Framingham Offspring Study. Diabetes 46: 1594-1600

31. Groop LC, Widen E, Ferrannini E (1993) Insulin resistance and insulin deficiency in the pathogenesis of type 2 (non-insulin-dependent) diabetes mellitus:errrors of metabolism or of methods? Diabetologia 36: 1326-1331

32. Ceriello A (1997) Acute hyperglycaemia and oxidative stress generation. Diabetic Med 14 [Suppl 3]: S45-S49

33. Ceriello A, Bortolotti N, Motz E et al. (1998) Meal-generated oxidative stress in type 2 diabetic patients. Diabetes Care 21: $1529-1533$ 